\title{
ANALYSIS OF THERMAL STRESSES AND STRAINS DEVELOPING DURING THE HEAT TREATMENT OF WINDMILL SHAFT
}

\begin{abstract}
In the paper the results of evaluation of the temperature and stress fields during four cycles of the heat treatment process of the windmill shaft has been presented. The temperature field has been calculated from the solution to the heat conduction equation over the whole heat treatment cycles of the windmill shaft. To calculate the stress field an incremental method has been used. The relations between stresses and strains have been described by Prandtl-Reuss equation for the elastic-plastic body. In order to determine the changes in the temperature and stress fields during heat treatment of the windmill shaft self-developed software utilizing the Finite Element Method has been used. This software can also be used to calculate temperature changes and stress field in ingots and other axially symmetric products. In the mathematical model of heating and cooling of the shaft maximum values of the strains have been determined, which allowed to avoid the crack formation. The critical values of strains have been determined by using modified Rice and Tracy criterion.
\end{abstract}

Keywords: stresses, fracture criterion, finite element method

\section{Introduction}

The currently observed global involvement in the development of renewable energy sources favours the production of wind energy, which is considered one of the cleanest and cheapest way of obtaining the green energy. In order to product this type of energy it is necessary to provide the appropriate materials for the construction of wind turbines. One of the components of wind turbine is the windmill shaft on which rotor is mounted. To ensure desired strength and quality requirements during the windmill shaft production process, it is necessary to use carefully prepared heat treatment, that provides required properties of the final product [1,2]. The proper selection of the parameters such as: rate of heating to the austenitization temperature, rate of cooling during quenching etc., allows to minimize stresses and strains that develop inside the heat treated ingot. This in turns allows to avoid defects caused by fractures.

Selection of the above mentioned parameters can be carried out based on numerical simulations, using specific software developed for solving this type of problems [1,3]. Using the results of numerical simulation in designing the heat treatment process allows to minimize the costs of the production.

\section{Mathematical model of heat transfer}

To determine the temperature field during the heat treatment of ingots the solution of the Fourier-Kirchhoff equation is required:

$$
\begin{aligned}
& \frac{1}{r} \frac{\partial}{\partial r}\left[\lambda(t) r \frac{\partial t(r, z, \tau)}{\partial r}\right]+\frac{\partial}{\partial z}\left[\lambda(t) \frac{\partial t(r, z, \tau)}{\partial z}\right]+ \\
& +q_{v}=\rho c \frac{\partial t}{\partial \tau}
\end{aligned}
$$

$(\tau>0 ; 0<r<R ; 0<z<l)$

where:

$\rho$ - density, $\mathrm{kg} / \mathrm{m}^{3}$,

$c$ - specific heat, $\mathrm{J} /(\mathrm{kg} \cdot \mathrm{K})$,

$t$ - temperature, ${ }^{\circ} \mathrm{C}$,

$R$ - radius, $\mathrm{m}$,

$l$ - length, $\mathrm{m}$,

$r, z$ - cylindrical coordinates,

$\lambda$ - thermal conductivity, $\mathrm{W} /(\mathrm{m} \cdot \mathrm{K})$,

$q_{v}$ - density of the internal heat source, $\mathrm{W} / \mathrm{m}^{3}$,

$\tau$ - time, $\mathrm{s}$.

The solution to this equation is time depended temperature field, which should comply with the boundary conditions on the ingot surface during the heat treatment. The boundary conditions have been assumed depending on the stage of the heat treatment 
process. The considered heat treating process has consisted of four operations: charge heating in the furnace chamber of, water or oil quenching, tempering and cooling in air. The boundary conditions applied to describe the heat transfer process during ingot heating in the chamber furnace have been introduced in the paper [4]. The heat flux released to the environment during the quenching process has been described by the Newton's equation:

$$
\dot{q}=\alpha\left(t_{s}-t_{a}\right)
$$

where:

$\alpha$ - heat transfer coefficient, $\mathrm{W} /\left(\mathrm{m}^{2} \cdot \mathrm{K}\right)$,

$t_{s}$ - ingot surface temperature, ${ }^{\circ} \mathrm{C}$,

$t_{a}$ - ambient temperature: water, oil, air or chamber furnace temperature, ${ }^{\circ} \mathrm{C}$.

The heat transfer coefficient between the ingot surface and quenching medium has been described basing on the experimental data. In case of water quenching the heat transfer coefficient is determined by the following equations [5]:

for $20^{\circ} \mathrm{C}<t<750^{\circ} \mathrm{C}$

$$
\begin{aligned}
\alpha= & 1.6544+0.117488 t-0.000466701 t^{2}+ \\
& +6.93222 \cdot 10^{-7} t^{3}-3.66133 \cdot 10^{4} t^{4}, \mathrm{~kW}\left(\mathrm{~m}^{2} \cdot \mathrm{K}\right)
\end{aligned}
$$

for $t<20^{\circ} \mathrm{C}$

$$
\alpha=0.51, \mathrm{~kW} /\left(\mathrm{m}^{2} \cdot \mathrm{K}\right)
$$

for $t>750^{\circ} \mathrm{C}$

$$
\alpha=0.55, \mathrm{~kW} /\left(\mathrm{m}^{2} \cdot \mathrm{K}\right)
$$

Heat transfer coefficient during quenching in oil has been described by the formulas [6]:

for $t<350^{\circ} \mathrm{C}$

$$
\begin{aligned}
\alpha= & 0.4207708-0.0003587 t- \\
& -4.52316 \cdot 10^{-6} t^{2}, \mathrm{~kW}\left(\mathrm{~m}^{2} \cdot \mathrm{K}\right)
\end{aligned}
$$

for $350^{\circ} \mathrm{C}<t<580^{\circ} \mathrm{C}$

$$
\begin{aligned}
\alpha= & 54.936190-0.408900 t+ \\
& +0.000981 t^{2}-7.255360 \cdot 10^{3}, \mathrm{~kW}\left(\mathrm{~m}^{2} \cdot \mathrm{K}\right)
\end{aligned}
$$

for $t>580^{\circ} \mathrm{C}$

$$
\begin{aligned}
\alpha= & -41.881512+0.239064 t- \\
& -0.000375 t^{2}+1.789258 \cdot 10^{3}, \mathrm{~kW}\left(\mathrm{~m}^{2} \cdot \mathrm{K}\right)
\end{aligned}
$$

The boundary conditions describing the heat transfer during the last stage of the heat treating process, that is cooling in air, have taken into account both the radiation and convection heat losses. More information about this model has been presented by Hadała in the paper [7].

\section{Numerical model of heat transfer}

The temperature field of the heat treated ingots has been calculated using numerical model which utilize the Finite Element Method (FEM) to the solution of the Fourier-Kirchhoff equation. Considering the shape of the ingot cross section and taking into account that the temperature field of the heated ingot has to be determined many times, axially symmetrical solution at the longitude section of the ingot has been applied. In order to determine the heat transfer between the ingot and the environment, the set of partial differential equations

$$
K_{i j}(\tau)+t_{j}(\tau)+C_{i j}(\tau) \dot{t}_{j}(\tau)=G_{j}(\tau)
$$

has to be solved, where:

$K_{i j}$ - thermal conductivity matrix,

$C_{i j}$ - thermal capacity matrix,

$G_{j}$ - heat load vector,

$t_{j}-$ nodes temperature vector,

$\dot{t}_{j}$ - temperature derivatives at nodes with respect to time.

Vector $G_{i j}$ and matrixes $C_{i j}, K_{i j}$ have been described by the integrals:

$$
\begin{gathered}
G_{i}=\sum \int_{\Omega_{e}} N_{i} q_{V} r d \Omega+\sum \int_{S e} N_{i}\left(\alpha t_{a}\right) r d S \\
C_{i j}=\sum \int_{\Omega_{\varepsilon}} \rho c_{p} N_{i} N_{j} r d \Omega
\end{gathered}
$$

$$
\begin{aligned}
K_{i j}= & \sum \int_{\Omega_{e}} \lambda\left(\frac{\partial N_{i}}{\partial r} \frac{\partial N_{j}}{\partial z}+\frac{\partial N_{i}}{\partial r} \frac{\partial N_{j}}{\partial z}\right) r d \Omega+ \\
& +\sum \int_{S_{e}} \alpha N_{i} N_{j} r d S
\end{aligned}
$$

where:

$N_{\mathrm{i}}-$ are shape functions,

$Q_{e}$ - volume of an element,

$S_{\mathrm{e}}-$ area of an element.

Shape function derivatives with respect to the global coordinates have been determined by the following equation

$$
\frac{\partial N_{k}}{\partial x_{i}}=J_{k i}^{-1} \frac{\partial N_{k}}{\partial \xi_{i}}
$$

The Jacobian determinant used to transform the global coordinates to natural coordinates has the form:

$$
D=\operatorname{det} J_{i j}=\operatorname{det}\left[\begin{array}{ll}
\frac{\partial r}{\partial \xi_{1}} & \frac{\partial r}{\partial \xi_{2}} \\
\frac{\partial z}{\partial \xi_{1}} & \frac{\partial z}{\partial \xi_{2}}
\end{array}\right]
$$

In case of the surface integrals the Jacobian determinant of the transformation has been described as

$$
D_{f}=\operatorname{det}\left[\frac{\partial r}{\partial \xi_{1}}\right]
$$

In order to calculate the correct values of thermal conductivity and thermal capacity matrixes and the heat load vector the surface integrals have been calculated only for elements lying on the surfaces of shaft. In the developed mathematical model four-nod elements with linear shape function have been used [8]: 


$$
N_{k}=\frac{1}{4}\left(1+\xi_{1} \xi_{1}^{k}\right)\left(1+\xi_{2} \xi_{2}^{k}\right)
$$

Derivatives of the global coordinates with respect to natural coordinates have the form:

$$
\begin{aligned}
& \frac{\partial r}{\partial \xi_{1}}=\frac{1}{4} \sum_{k=1}^{4} \xi_{1}^{k}\left(1+\xi_{2} \xi_{2}^{k}\right) r^{k} \\
& \frac{\partial r}{\partial \xi_{2}}=\frac{1}{4} \sum_{k=1}^{4} \xi_{2}^{k}\left(1+\xi_{1} \xi_{1}^{k}\right) r^{k} \\
& \frac{\partial z}{\partial \xi_{1}}=\frac{1}{4} \sum_{k=1}^{4} \xi_{1}^{k}\left(1+\xi_{2} \xi_{2}^{k}\right) z^{k} \\
& \frac{\partial z}{\partial \xi_{2}}=\frac{1}{4} \sum_{k=1}^{4} \xi_{2}^{k}\left(1+\xi_{1} \xi_{1}^{k}\right) z^{k}
\end{aligned}
$$

where: $\xi_{i}^{k}$ - natural coordinates of an element.

Assuming a linear change of temperature versus time for $\left(\tau_{o}<\tau<\tau_{o}+\Delta \tau\right)$ and using the Galerkin scheme of integration, the set of equation has been obtained [8]:

$$
A_{i j}(\tau) t_{j}(\tau+\Delta \tau)=B_{i}(\tau)
$$

This set of equation (19) allows calculating the temperature of the material after the time increment $\Delta \tau$.

Vector $B_{\mathrm{i}}$ and the matrix $A_{i j}$ in the equation (19) have the following form:

$$
\begin{aligned}
A_{i j}(\tau)=\frac{1}{3} K_{i j}(\tau)+\frac{1}{2 \Delta \tau} C_{i j}(\tau) \\
B_{i}(\tau)=\left[\frac{1}{2 \Delta \tau} C_{i j}(\tau)-\frac{1}{6} K_{i j}(\tau)\right] t_{j}(\tau)- \\
-\frac{1}{3} G_{i}\left(\tau-\tau_{i}\right)+\frac{5}{6} G_{i}(\tau)
\end{aligned}
$$

The set of equations (19) can be obtained calculating integrals: (10), (11) and (12) over all elements. The set of linear equation resulting from this operation has been solved using the Gauss elimination method.

\section{Stress and strain model}

During the whole heat treatment process thermal stresses develop inside the heat and cooled ingots, that are caused by nonuniform temperature field and phase transformation. This stresses may lead to elastic or plastic deformations. However, when the limit of material formability is exceeded, existing voids develop and local fractures occur and in some cases the steel cracks. There are methods that allow to determine the stress and strain fields inside the materials that are under heat load. The finite element method has been applied to determine the stress and strain fields during the ingots heat treatment process $[8,9]$. The specific steps of the solution were as follows:
- expressing the displacement field $\{\underline{\Delta}\}$ as a function of nodes displacement $\{\Delta\}$. To define these field, the shape function values have to be determined.

- expressing the strain field $\{\varepsilon\}$, as a function of nodes displacement vector, by differentiation of displacement field according to small elastic-plastic strain tensor definition.

- determining the relationship between stress and stains and defining the stress as the function of nodes degrees of freedom.

- determining the relationship between the forces at nodes and stresses from the condition of equilibrium between the nodal forces and the stresses power inside an element.

Due to the possibility of plastic deformation and time dependent heating conditions, the incremental method has been used to determined the stress field. The relationship between the stresses and strains increments have been determine using Prandtl-Reuss equations. The methodology of stress and strain fields determination has been described in the monograph [9].

In order to determine the material failure point the Rice and Tracy crack criterion has been used:

$$
\bar{\varphi}_{f}=C_{R T} \exp \left(-\frac{3}{2} \frac{\sigma_{m}}{\sigma_{p}}\right)
$$

where:

$\bar{\varphi}_{f}$ - effective logarithmic strain,

$\sigma_{p}-$ effective stress,

$\sigma_{m}-$ mean stress.

The results of the investigation presented in the paper [10] have shown a good accuracy of criterion (22) in determining the moment of material destruction.

Criterion (22) provides that the material destruction occurs when the right side of the equation exceeds the value of the effective logarithmic strain $\bar{\varphi}_{f}$ defined during the uniaxial tensile test at the moment of fracture. The constant $C_{R T}$ has been determined from the stress and strain state definition for an uniaxial tensile test. Finally, the modified Rice and Tracy criterion has been obtained:

$$
\begin{gathered}
\bar{\varphi}_{f}=\exp (0.5) \exp \left(-\frac{3}{2} \frac{\sigma_{m}}{\sigma_{p}}\right) \text { for } \sigma_{m}>0 \\
\bar{\varphi}_{f}=0 \quad \text { for } \quad \sigma_{m}<0
\end{gathered}
$$

According to the criterion (23), cracking may occur if the parameter $\bar{\varphi}_{f}$ exceeds the maximum value of the logarithmic strain determined from the uniaxial tensile test of the sample taken from the shaft steel.

\section{Numerical calculations}

Numerical calculation have been conducted for the two cases of the heat treatment process of windmill shaft. Both heat treatment processes have consisted of four operations, there were: ingot heating in the chamber furnace, quenching, tempering and 
cooling in air. The cases differed from each other in the type of quenching medium. In Case I water and in Case II oil. The total time of the whole heat treatment process was the same for each considered processes and equaled to 8500 minutes. The first operation - heating to an austenization temperature of $860^{\circ} \mathrm{C}$ - was the same in both cases and equaled to 2240 minutes. The duration of the other heat treatment differed for Case I and Case II. The time of each operation for both considered heat treatment processes is presented in table 1 .

TABLE 1

Duration of the heat treatment operations

\begin{tabular}{|l|c|c|}
\hline \hline \multirow{2}{*}{\multicolumn{1}{c|}{ Operation }} & Case I & Case II \\
\cline { 2 - 3 } & Time, min & Time, min \\
\hline Heating to $860^{\circ} \mathrm{C}$ & 2240 & 2240 \\
\hline Quenching in water & 40 & - \\
\hline Quenching in oil & - & 80 \\
\hline Tempering & 1930 & 1880 \\
\hline Cooling in air & 4290 & 4300 \\
\hline
\end{tabular}

The ingot initial temperature assumed for calculation was $20^{\circ} \mathrm{C}$. The chemical composition of steel was as follows: $\mathrm{C}=0.34 \%, \mathrm{Mn}=0.55 \%, \mathrm{Si}=0.27 \%, \mathrm{Cr}=1.4 \%, \mathrm{Ni}=1.5 \%$. Thermophysical properties of steel were selected based on steel chemical composition. The limit value of the effective logarithmic strain determined in the tensile test at temperature $500^{\circ} \mathrm{C}$ was equal to 0.13 . In figure 1 , the scheme of the windmill shaft with marked cross-sections at which the results of computations have been presented. Selected for the analysis three cross-sections of the windmill shaft are characterized by different outer diameters. In figure 2 the scheme of the heat treatment process has been presented. The calculations conducted for the first operation has shown that the assumed time of heating to the austenization temperature has been selected properly. The temperature distributions along the ingot radius has been similar at each considered cross-section. In figures 3-5 and 6-8 the distributions of the ef-

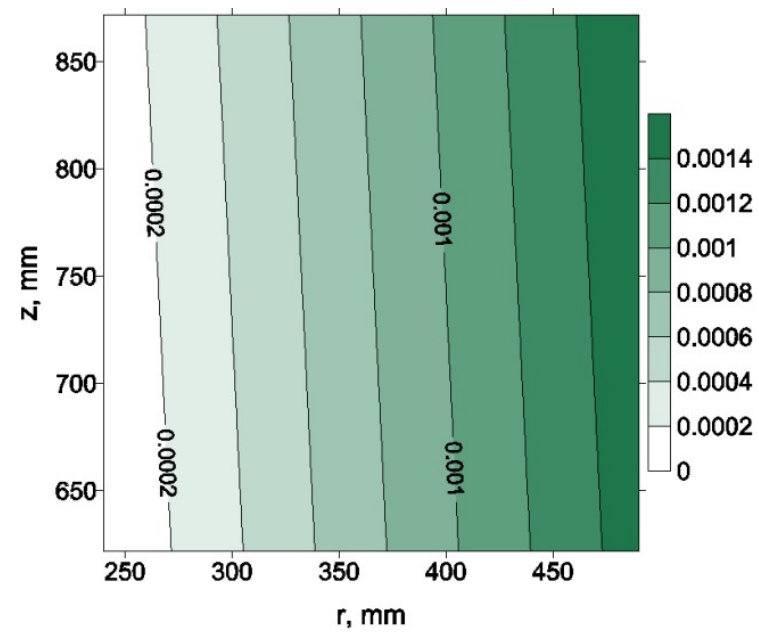

Fig. 3. The distribution of the effective logarithmic strain in the ingot 1-1 cross-section after heating to $860^{\circ} \mathrm{C}$ fective logarithmic strain and the mean stress, respectively after heating to the austenization temperature has been presented. The values of the effective logarithmic strain have been very small and have not exceed 0.002 at any considered cross-section of the ingot (Fig. 3-5). Higher values of the effective logarithmic strain have been observed at the windmill shaft surface. It is acceptable, taking into account, that the mean stress in the entire volume of the heated ingot was negative (compressive) (Fig. 6-8).

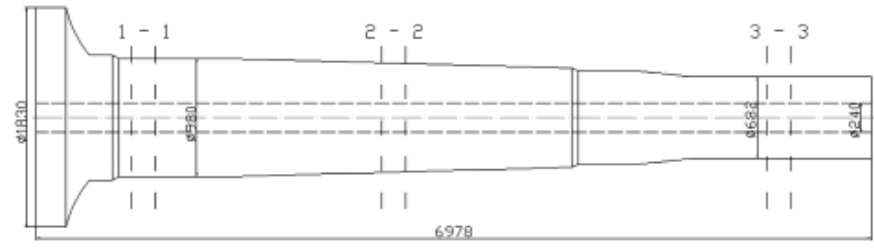

Fig. 1. Scheme of the heat treated windmill shaft

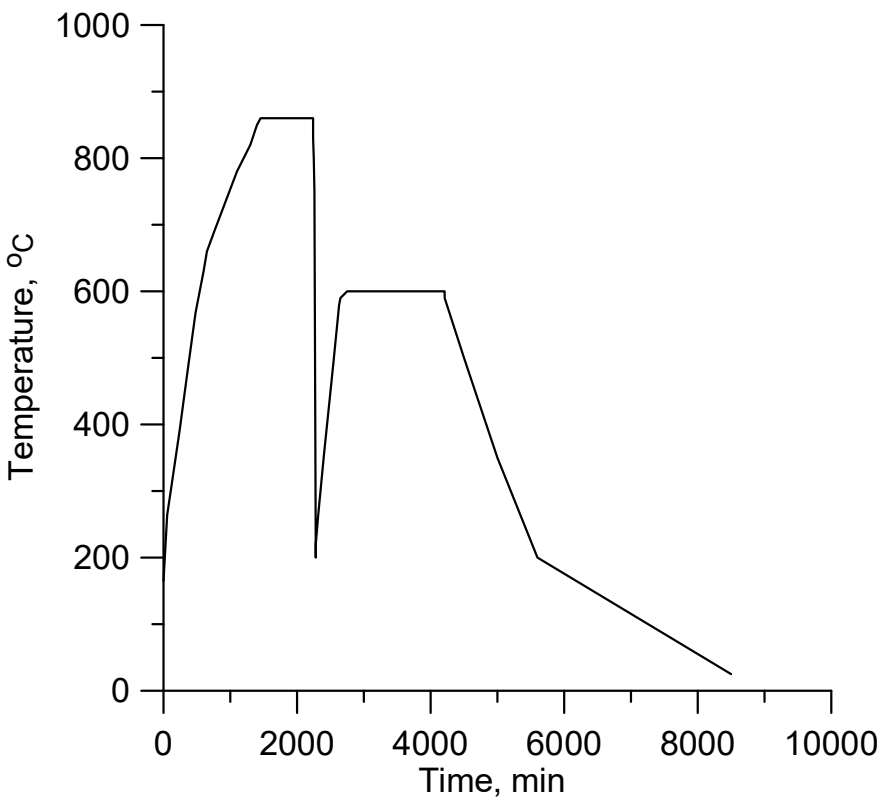

Fig. 2. Scheme of the heat treatment process for considered cases

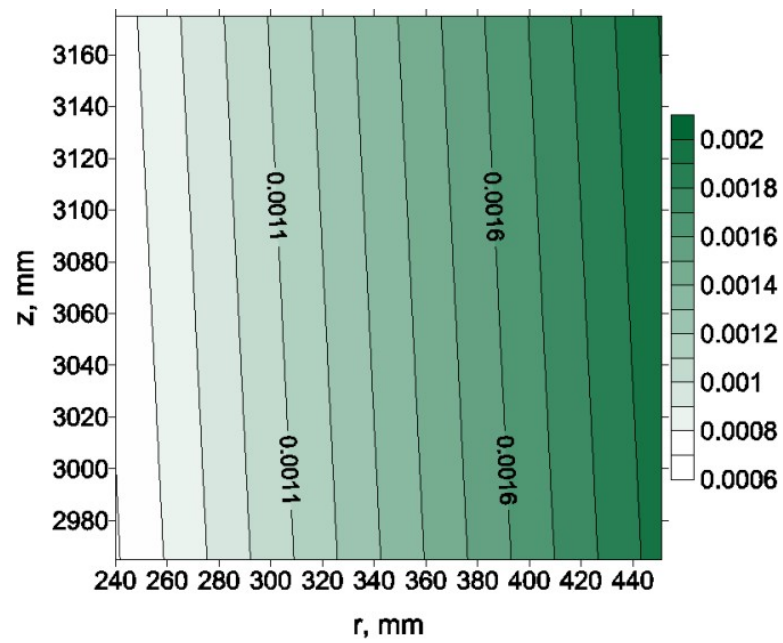

Fig. 4. The distribution of the effective logarithmic strain in the ingot 2-2 cross-section after heating to $860^{\circ} \mathrm{C}$ 


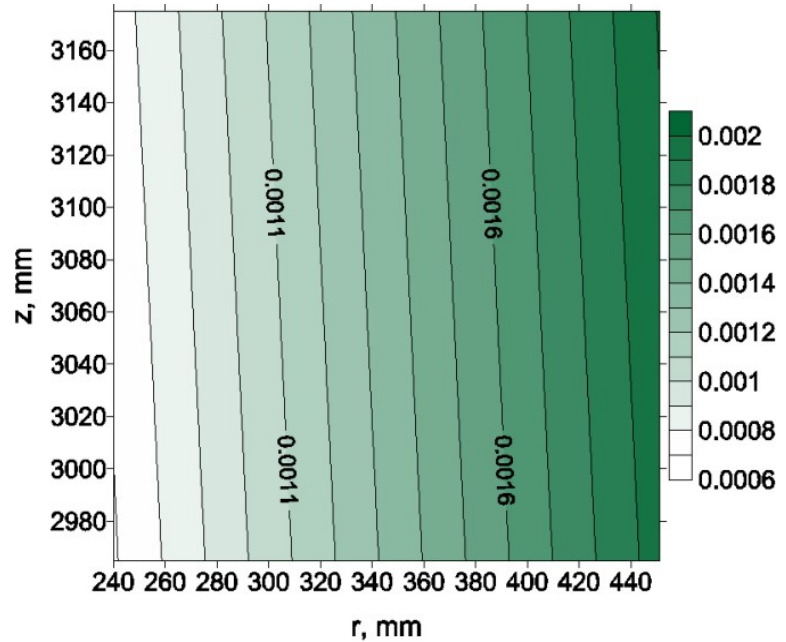

Fig. 5. The distribution of the effective logarithmic strain in the ingot 3-3 cross-section after heating to $860^{\circ} \mathrm{C}$

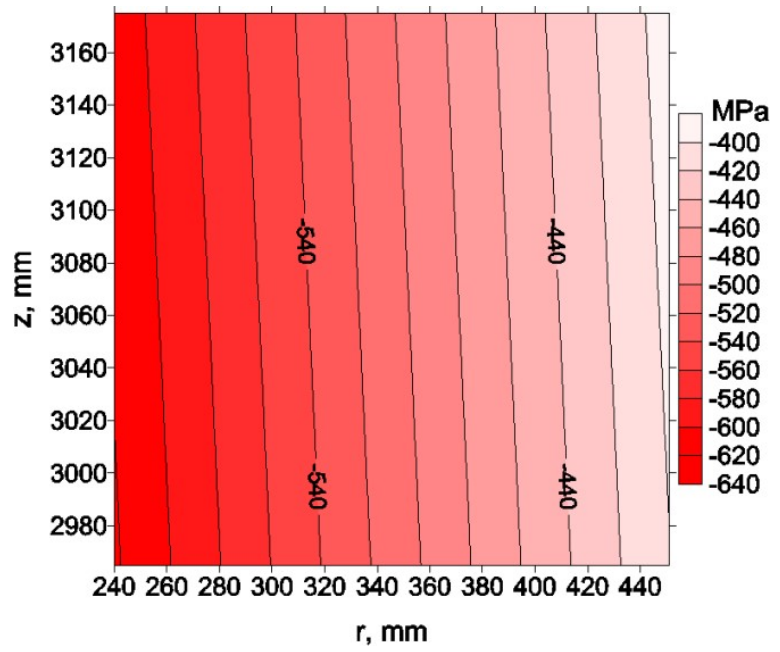

Fig. 7. The mean stress distribution in the ingot $2-2$ cross-section after heating to $860^{\circ} \mathrm{C}$

After the water quenching process the temperature distribution along the radius was different at each cross-section. In order to compare the temperature distribution three characteristic points has been selected. First point was located at the internal surface of the ingot, the second one in the middle of the wall thickness and the third one was placed at the outer surface of the ingot. The results of calculations have indicated that after the water quenching process (after 2280 minutes from the start of the heat treatment process (Tab. 1), the highest difference in the temperature distribution has been observed in 1-1 crosssection. There, the values of temperature at the characteristic points have been equal to $61^{\circ} \mathrm{C}, 222^{\circ} \mathrm{C}$ and $103^{\circ} \mathrm{C}$, respectively, counting from the internal surface of the ingot. The maximum difference between calculated temperatures in 1-1 cross-section was equal to $161 \mathrm{~K}$. At $2-2$ cross-section the difference in the temperature distribution along the ingot radius has been significantly lower. The maximum difference has not exceeded $50 \mathrm{~K}$. In case of 3-3 cross-section, after the water quenching process,

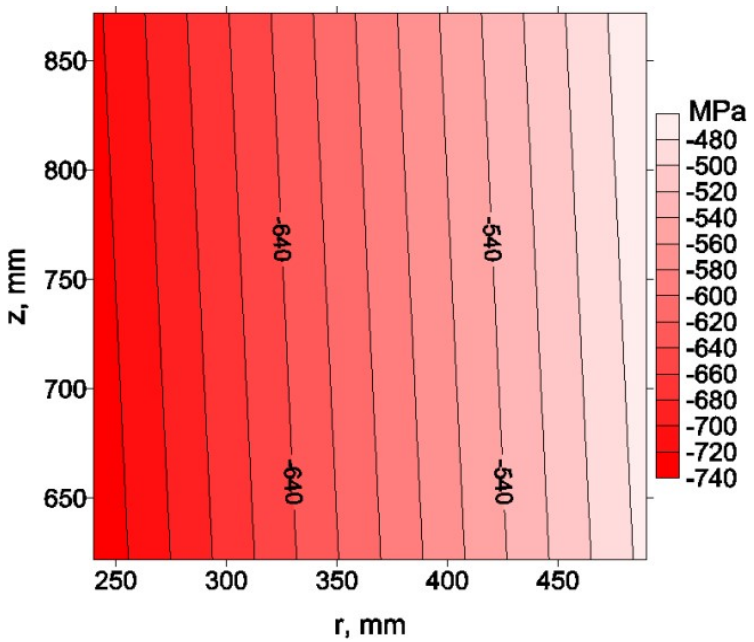

Fig. 6. The mean stress distribution in the ingot 1-1 cross-section after heating to $860^{\circ} \mathrm{C}$

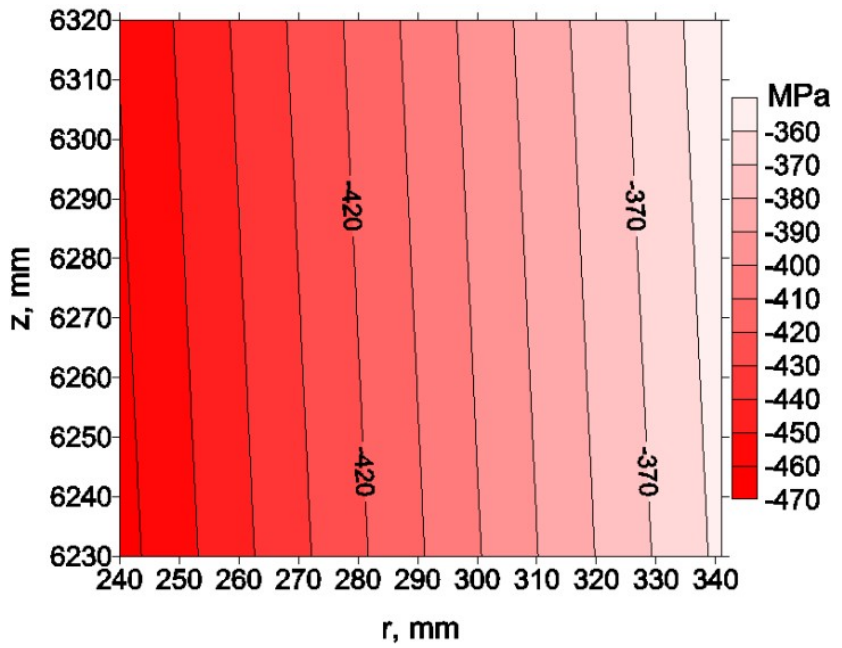

Fig. 8. The mean stress distribution in the ingot 3-3 cross-section after heating to $860^{\circ} \mathrm{C}$

the entire part of the ingot has had the same temperature equal to $20^{\circ} \mathrm{C}$. Such differences in the values of temperatures between particular cross-sections of the ingot are caused by a large difference in the ingot outer diameter. The effective logarithmic strain after the water quenching process was still very small of about 0.001 at each cross-section that have been taken under consideration (Fig. 9-11). The mean stress values at each considered cross-section at the end of the quenching process were positive, it means that the shaft material is under tensile conditions (Fig. 12-14). The highest values of the mean stress have occurred at each considered cross-section of the ingot, near the internal surface of the windmill shaft. There, the mean stress values have not exceeded $480 \mathrm{MPa}$ at the 1-1 cross-section (Fig. 12), 540 $\mathrm{MPa}$ at 2-2 cross-section (Fig. 13) and $615 \mathrm{MPa}$ at 3-3 crosssection (Fig. 14).

The temperature distribution in the whole ingot after the tempering operation has been homogeneous, and resulted from the length of the heating time in the furnace. In the Case I this 


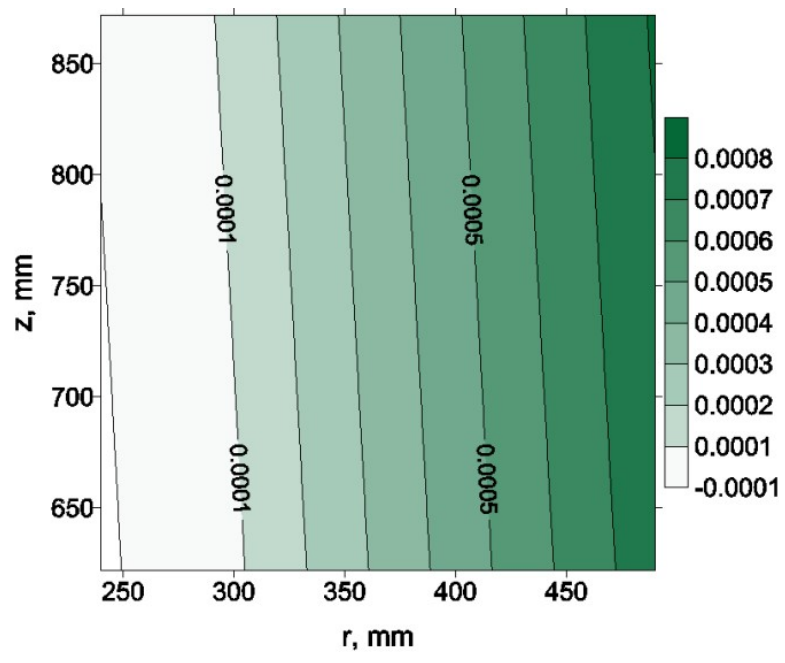

Fig. 9. The distribution of the effective logarithmic strain in the ingot 1-1 cross-section after quenching in water (Case I)

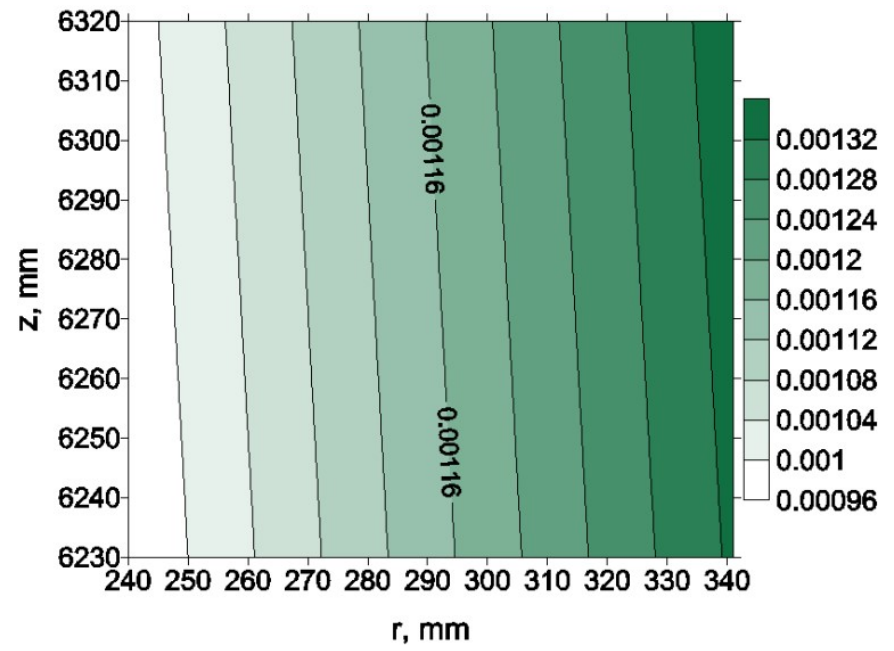

Fig. 11. The distribution of the effective logarithmic strain in the ingot 3-3 cross-section after quenching in water (Case I)

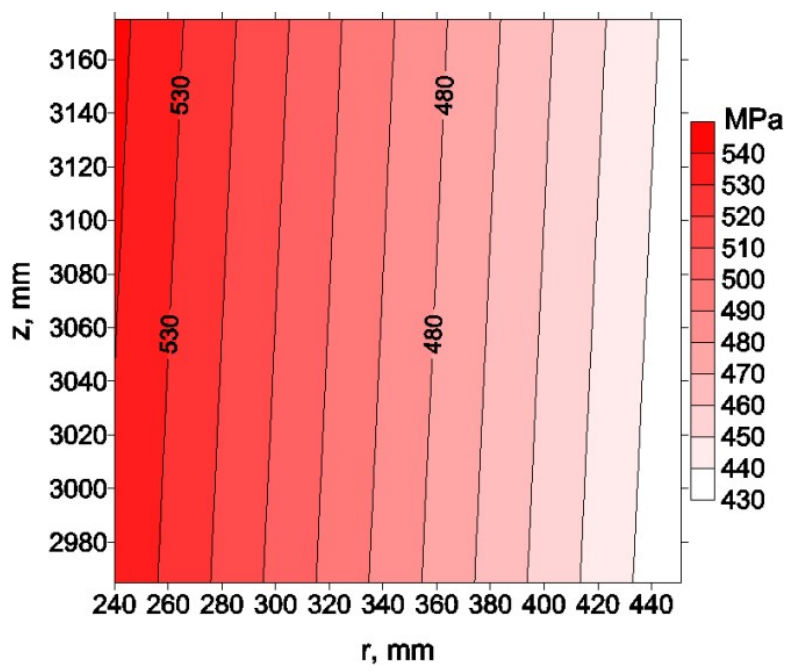

Fig. 13. The mean stress distribution in the ingot 2-2 cross-section after quenching in water (Case I)

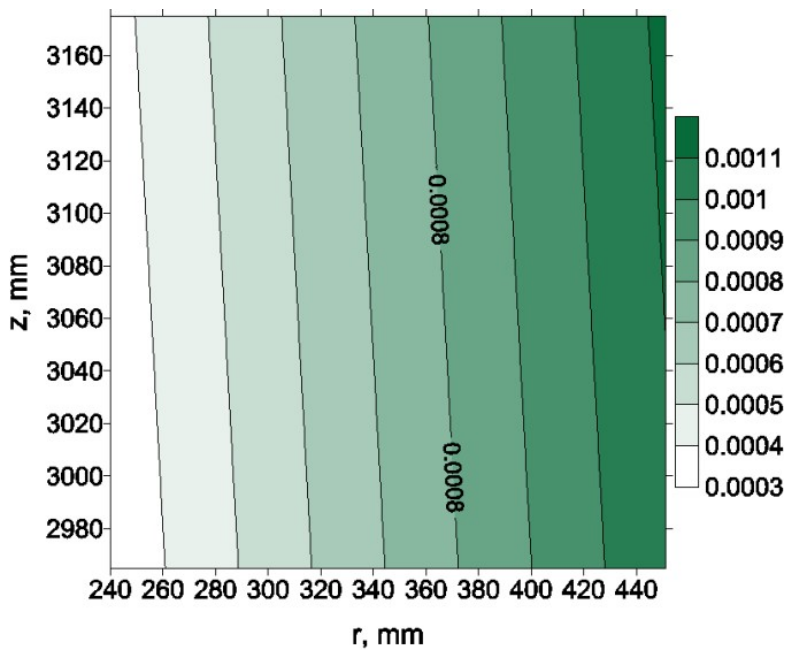

Fig. 10. The distribution of the effective logarithmic strain in the ingot 2-2 cross-section after quenching in water (Case I)

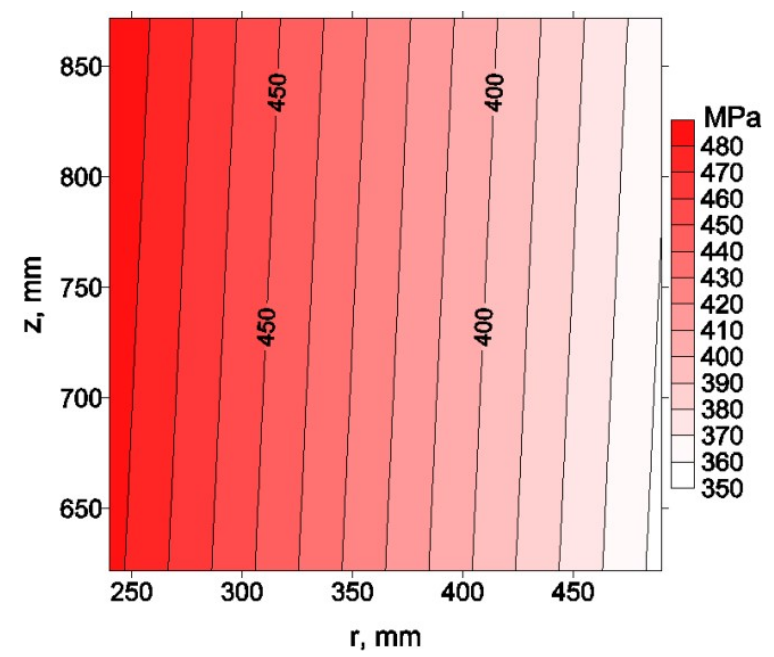

Fig. 12. The mean stress distribution in the ingot 1-1 cross-section after quenching in water (Case I)

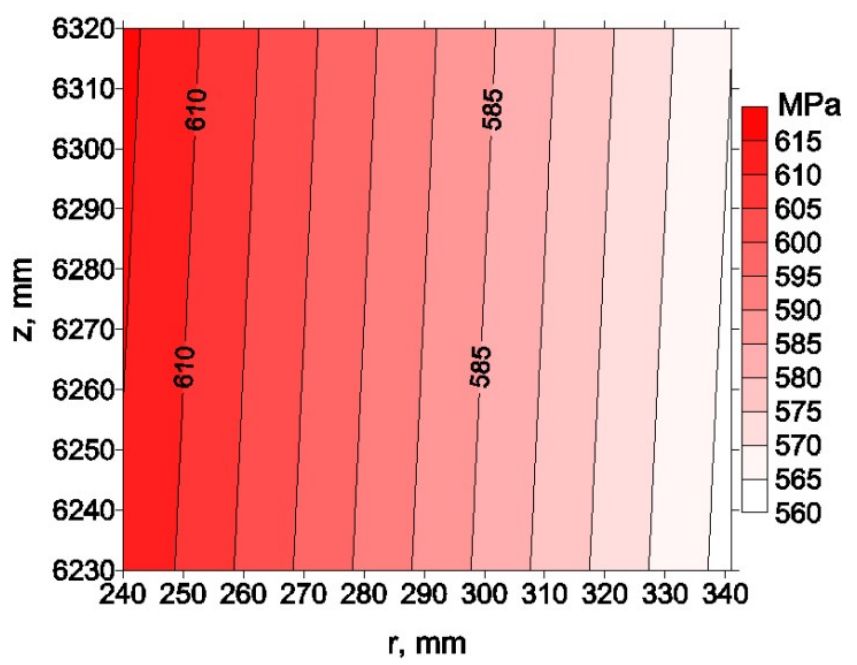

Fig. 14. The mean stress distribution in the ingot 3-3 cross-section after quenching in water (Case I) 
time was about 32 hours (Tab. 1), ingot temperature equaled to $600^{\circ} \mathrm{C}$. The effective logarithmic strain after tempering has been slightly higher from that reported for the previous heat treatment operations. In the 1-1 cross-section which is characterized by the largest ingot radius, the maximum values of the effective logarithmic strain have been the smallest at a level of 0.0016 (Fig. 15). In 2-2 cross-section the maximum values of the effective logarithmic strain have been equal to 0.0024 (Fig. 16) and in the 3-3 cross-section the highest values of the effective logarithmic strain have occurred of about 0.003 (Fig. 17). In all considered cross-sections the highest values of the effective logarithmic strain have been developed near the ingot outer surface. The main stress distributions after tempering operation in each cross-section of the ingot have been opposite to the preceding operation of water quenching. The lowest vales of

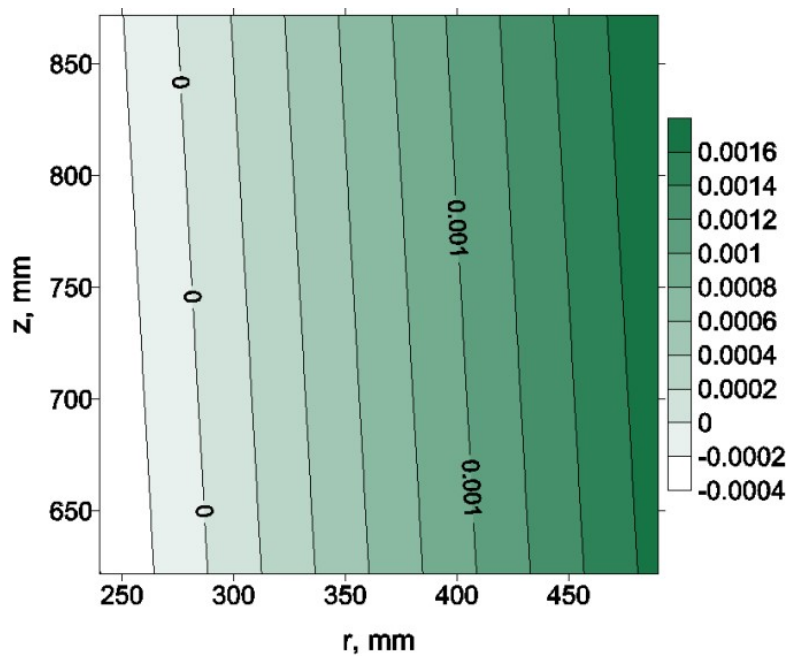

Fig. 15. The distribution of the effective logarithmic strain in the ingot 1-1 cross-section after tempering (Case I)

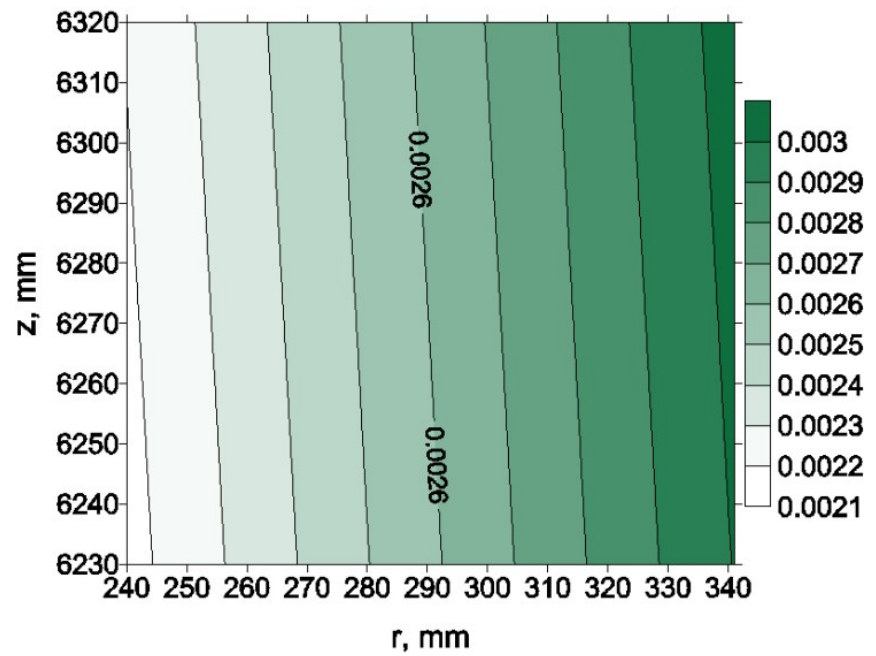

Fig. 17. The distribution of the effective logarithmic strain in the ingot 3-3 cross-section after tempering (Case I) the mean stress have occurred near the internal surface of the ingot. However, tempering has caused that inside the heated ingot compressive stresses have developed (Fig. 18-20). The last heat treatment operation - cooling in air-has lasted about 72 hours. After this time the temperature inside the windmill shaft has dropped to $50^{\circ} \mathrm{C}$. After this heat treatment operation the effective logarithmic strain has decreased to approximately 0.001 in each considered cross-section of the ingot (Fig. 21-23). The maximum mean stress at the end of heat treatment process, that included ingot quenching in water, has been located near the ingot internal surface. The maximum values of the mean stress have not exceed $740 \mathrm{MPa}$ in the ingot 1-1 cross-section, 680 $\mathrm{MPa}$ in 2-2 cross-section and $590 \mathrm{MPa}$ in 3-3 cross-section. The minimum value of the mean stress after heat treatment process has not dropped below $500 \mathrm{MPa}$.

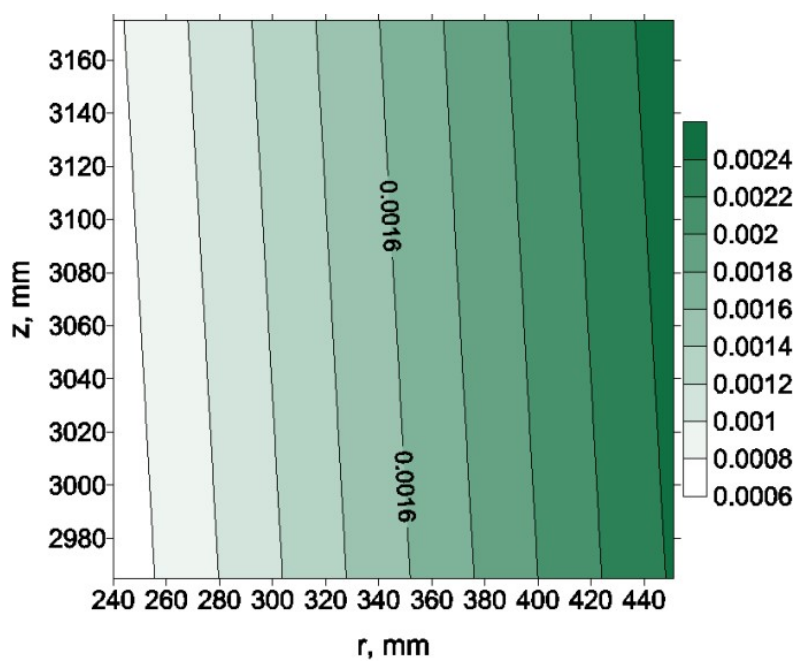

Fig. 16. The distribution of the effective logarithmic strain in the ingot 2-2 cross-section after tempering (Case I)

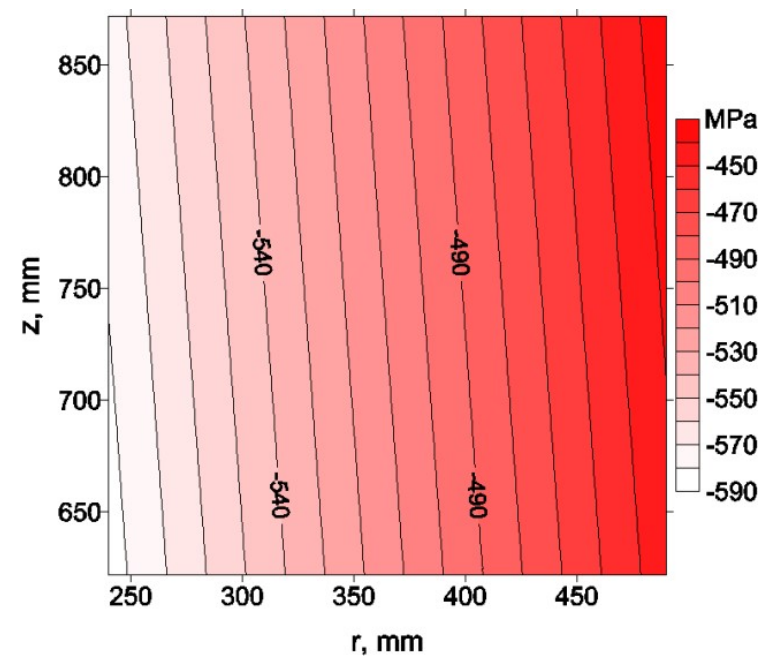

Fig. 18. The mean stress distribution in the ingot 1-1 cross-section after tempering(Case I) 


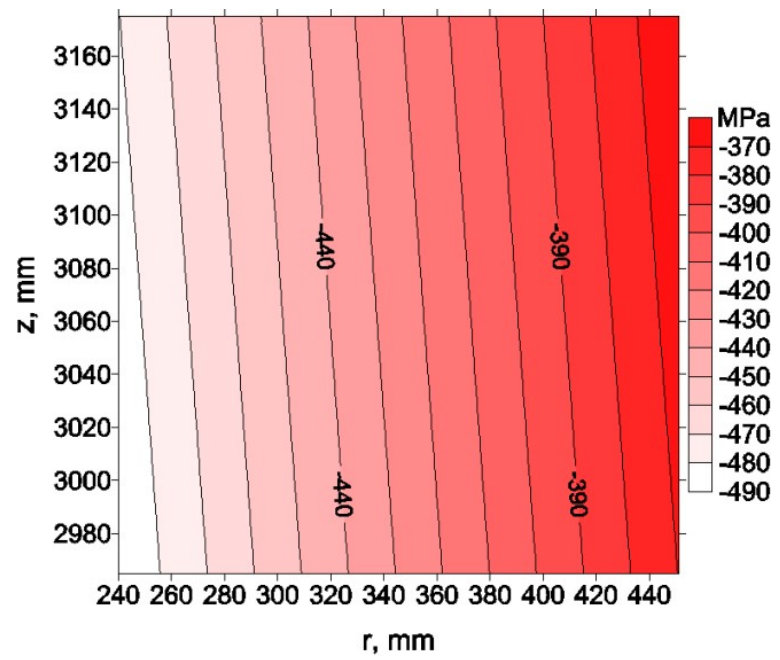

Fig. 19. The mean stress distribution in the ingot $2-2$ cross-section after tempering (Case I)

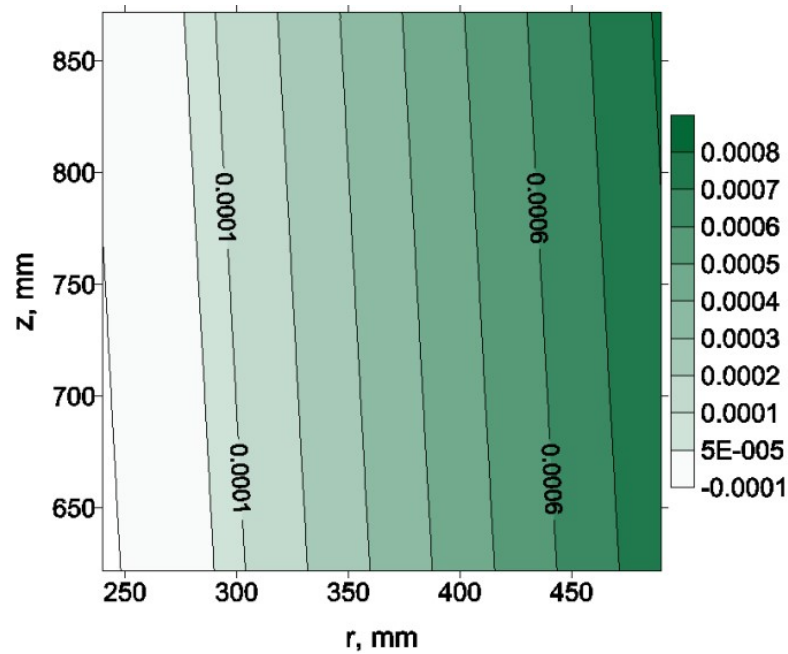

Fig. 21. The distribution of the effective logarithmic strain in the ingot 1-1 cross-section after cooling in air (Case I)

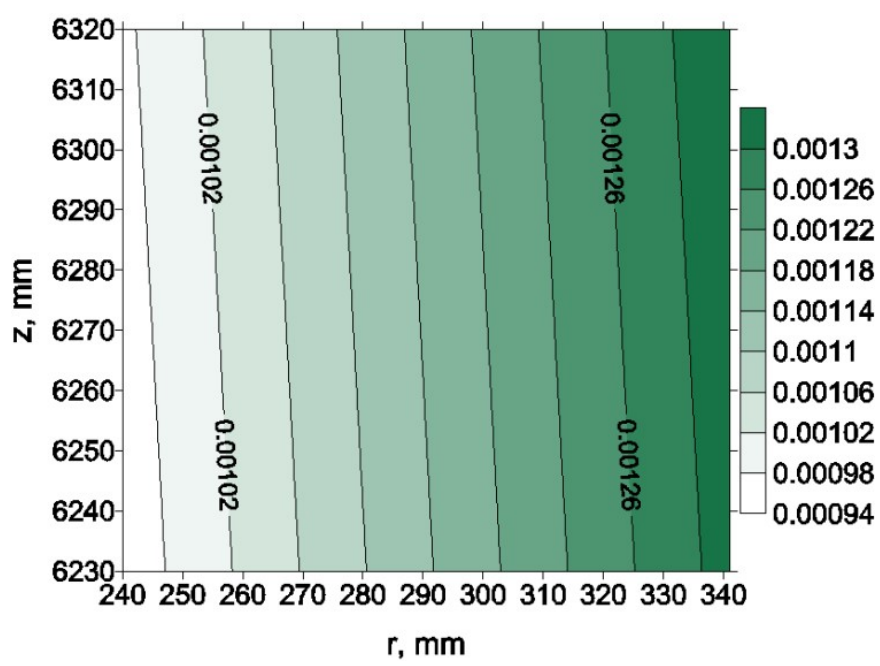

Fig. 23. The distribution of the effective logarithmic strain in the ingot 3-3 cross-section after cooling in air (Case I)

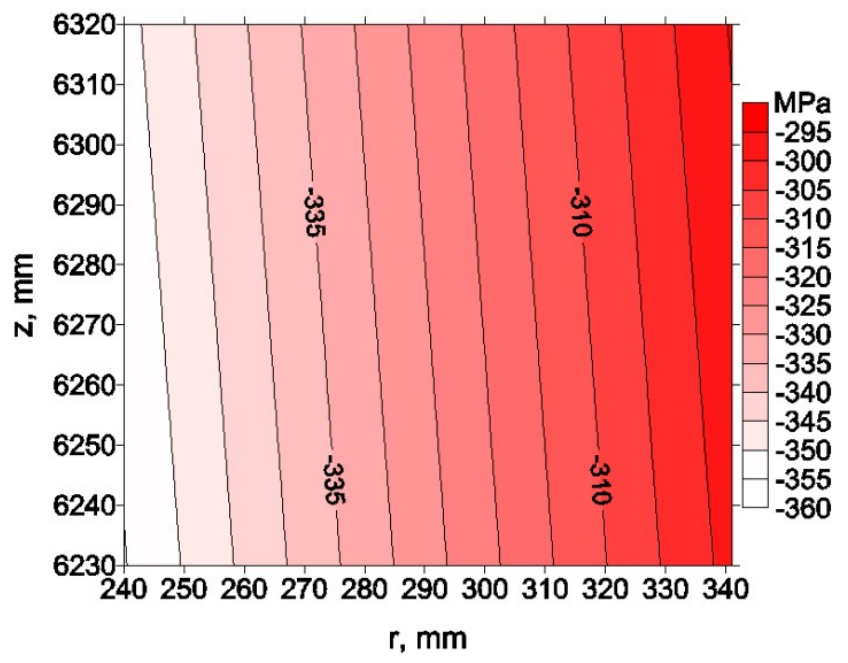

Fig. 20. The mean stress distribution in the ingot 3-3 cross-section after tempering (Case I)

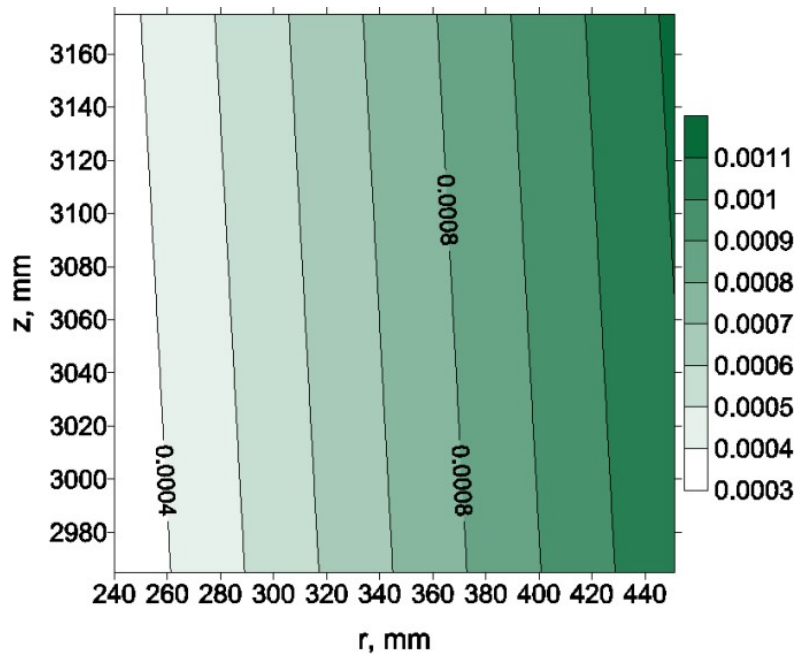

Fig. 22. The distribution of the effective logarithmic strain in the ingot 2-2 cross-section after cooling in air (Case I)

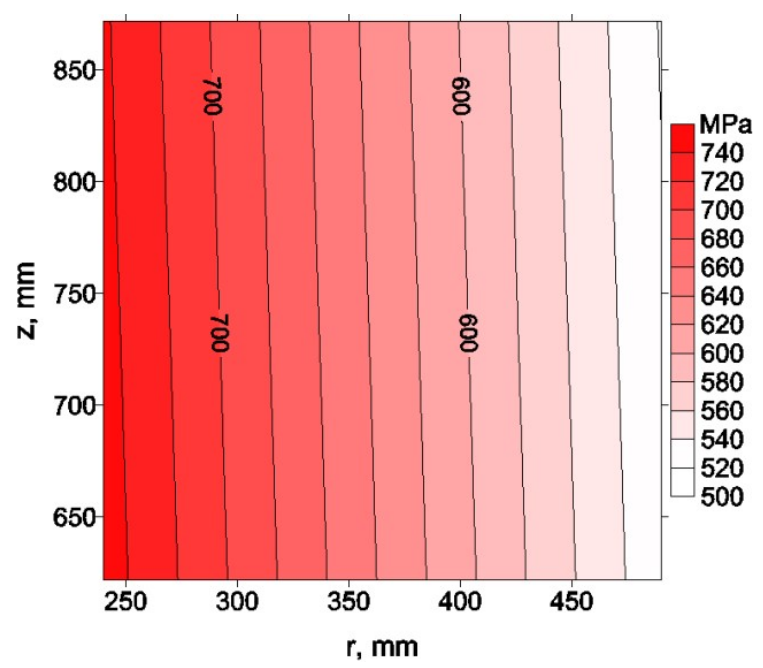

Fig. 24. The mean stress distribution in the ingot 1-1 cross-section after cooling in air (Case I) 


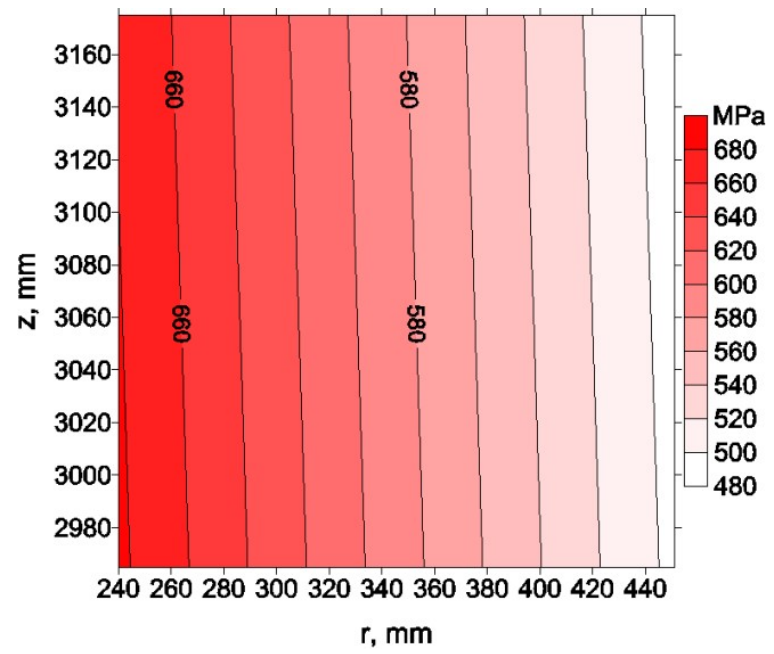

Fig. 25. The mean stress distribution in the ingot 2-2 cross-section after cooling in air (Case I)

In the heat treatment process which included quenching in oil and has been considered as Case II, the first operation of the ingot heating to $680^{\circ} \mathrm{C}$, has been the same as in Case I, and resulted in the same distributions of temperature, effective logarithmic strain and mean stress. It has caused that the total time of the quenching operation was about 40 minutes longer from the quenching in water (Tab.1). The maximum temperature difference between characteristic points of the ingot (the same as mentioned in Case I) has been smaller to the case of water quenching. The temperature deference was equal to $25 \mathrm{~K}$ in the 1-1 cross-section of the ingot, and to $16 \mathrm{~K}$ in the $2-2$ crosssection. For example, the values of temperature at characteristic points over the ingot radius starting from the internal surface of the ingot ware equal to $122^{\circ} \mathrm{C}, 128^{\circ} \mathrm{C}, 147^{\circ} \mathrm{C}$ in $1-1$ crosssection. Similarly, as in case of water quenching, temperature distribution along the ingot radius in 3-3 cross-section has been nearly the same at a level of $50^{\circ} \mathrm{C}$ after the oil quenching process. The effective logarithmic strain after the oil quenching process

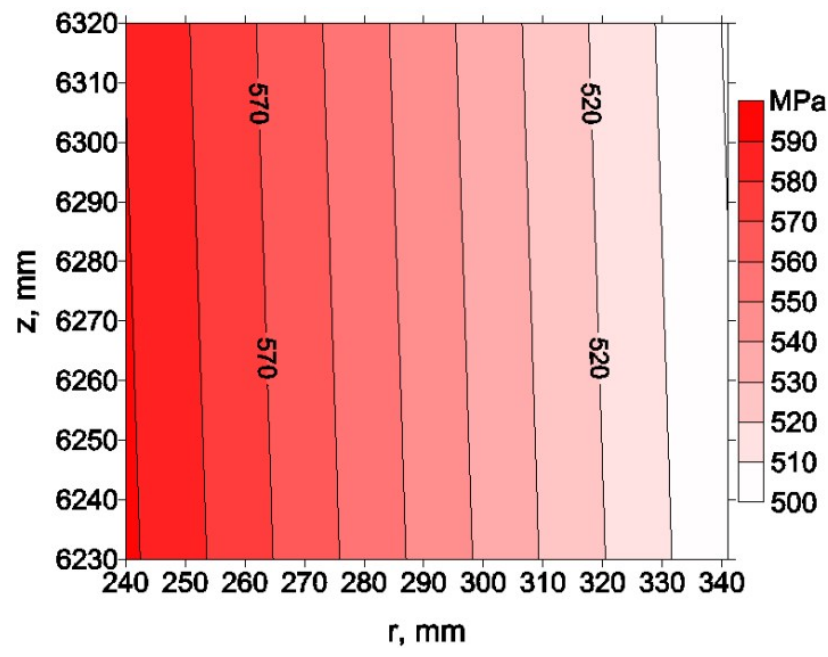

Fig. 26. The mean stress distribution in the ingot 3-3 cross-section after cooling in air (Case I)

was smaller than the one obtained during water quenching, it has not exceed 0.001 (Fig. 27-29). Similarly as after the water quenching operation, positive mean stresses at each considered cross-section indicate that inside the ingot tensile stresses has developed (Fig. 30-32). The maximum mean stress at any considered cross-section has not exceed $570 \mathrm{MPa}$ (Fig. 30-32). Also, the mean stress distributions in the all ingot cross-sections is the same as the one observed after water quenching operation (Fig. 12-14).

The tempering operation in Case II has been about 1 hour shorter then in Case I. This resulted from higher and more homogenous temperature distribution inside the ingot after quenching operation. The values of the effective logarithmic strain after tempering operation in Case II have been lower than in the previously presented case, and they do not exceed 0.002 in any considered ingot cross-section (Fig. 33-35). The effective logarithmic strain distributions were similar to those obtained for the analogous operation considered in the Case I. The mean

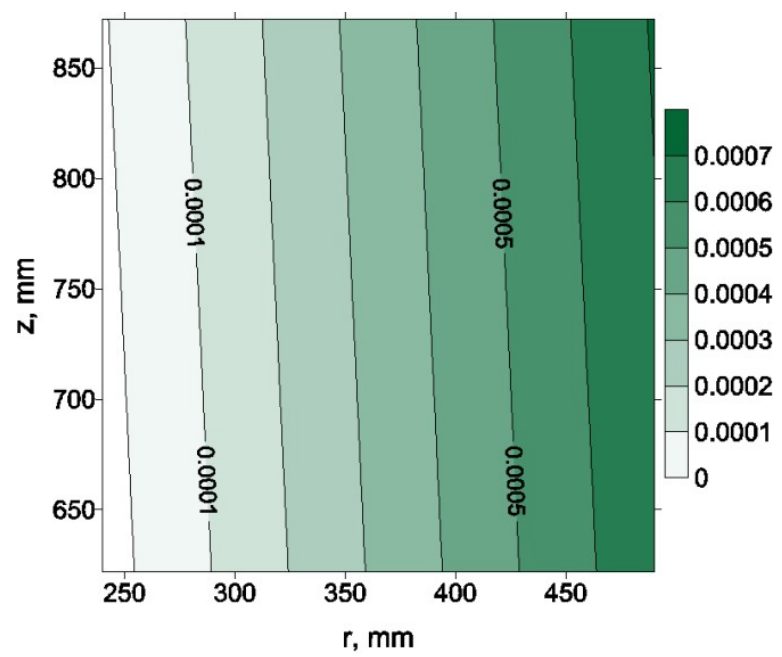

Fig. 27 The distribution of the effective logarithmic strain in the ingot 1-1 cross-section after quenching in oil (Case II)

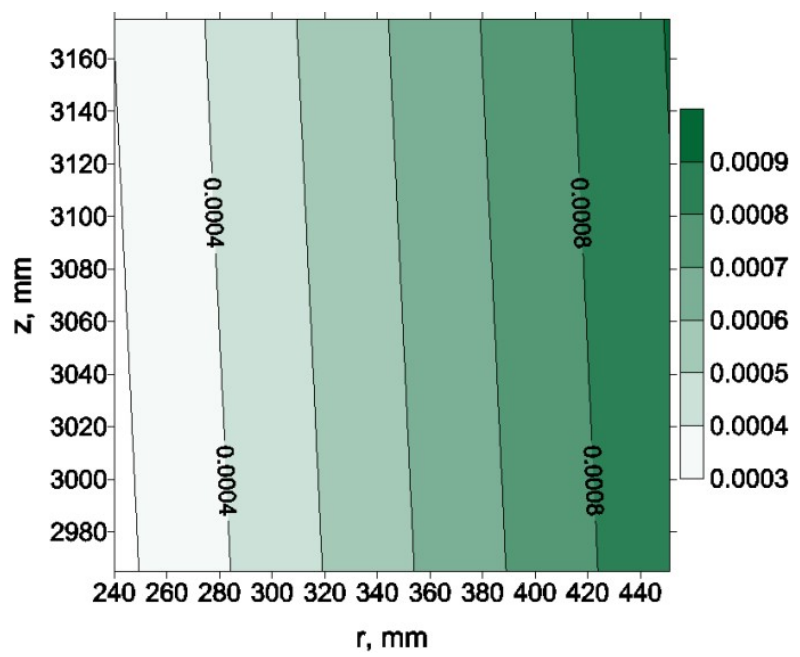

Fig. 28 The distribution of the effective logarithmic strain in the ingot 2-2 cross-section after quenching in oil (Case II) 
468

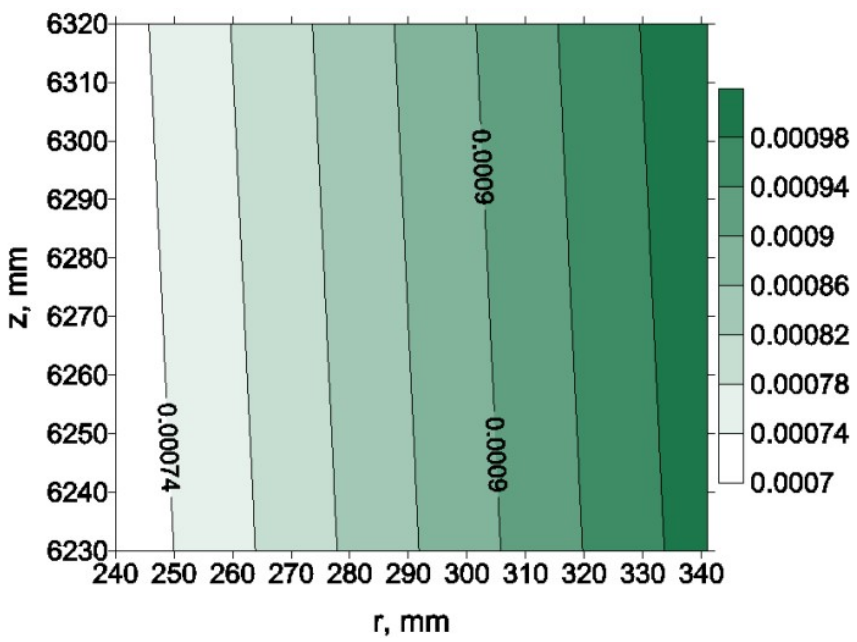

Fig. 29. The distribution of the effective logarithmic strain in the ingot 3-3 cross-section after quenching in oil (Case II)

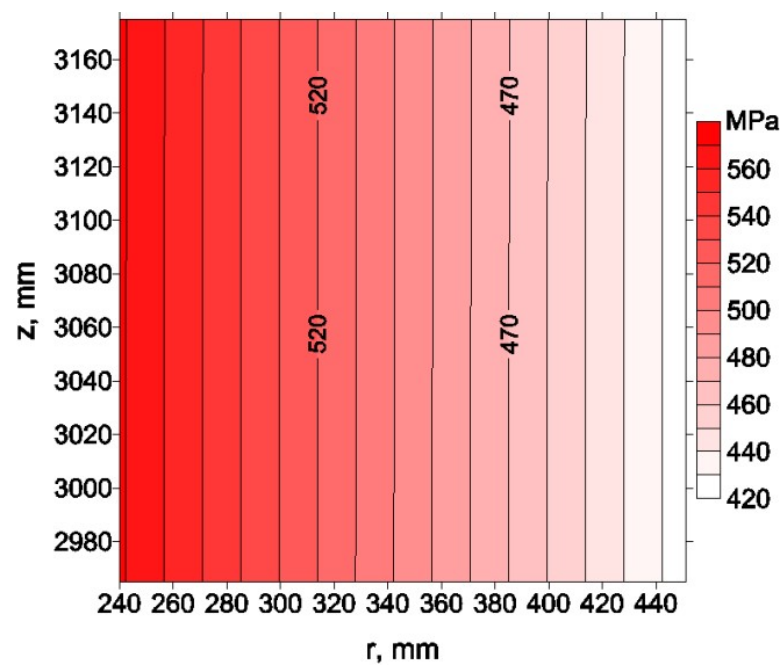

Fig. 31. The mean stress distribution in the ingot 2-2 cross-section after quenching in oil (Case II)

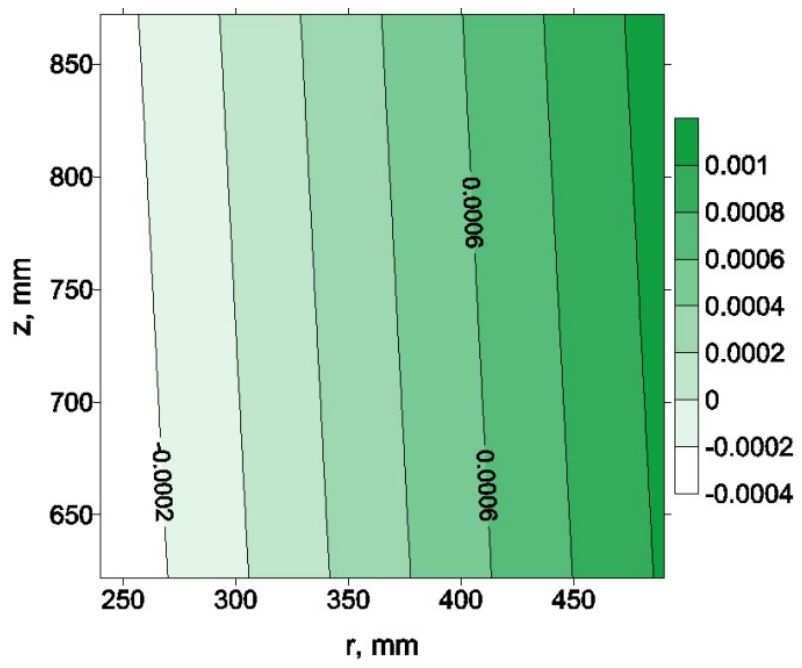

Fig. 33. The distribution of the effective logarithmic strain in the ingot 1-1 cross-section after tempering (Case II)

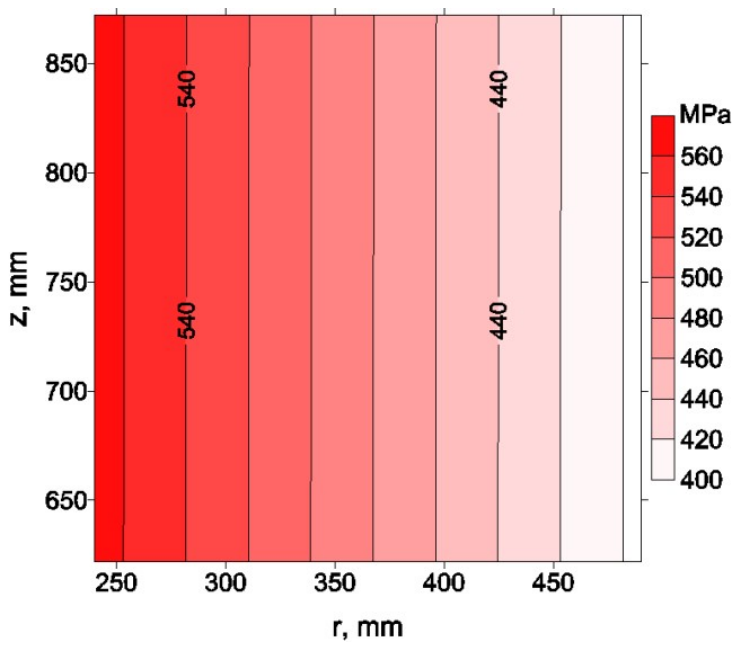

Fig. 30. The mean stress distribution in the ingot 1-1 cross-section after quenching in oil (Case II)

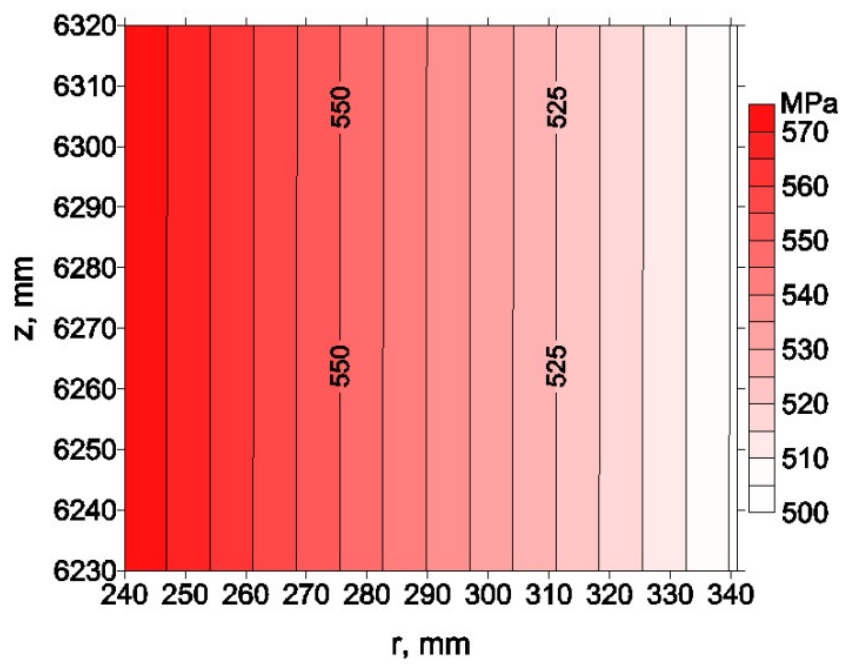

Fig. 32. The mean stress distribution in the ingot 3-3 cross-section after quenching in oil (Case II)

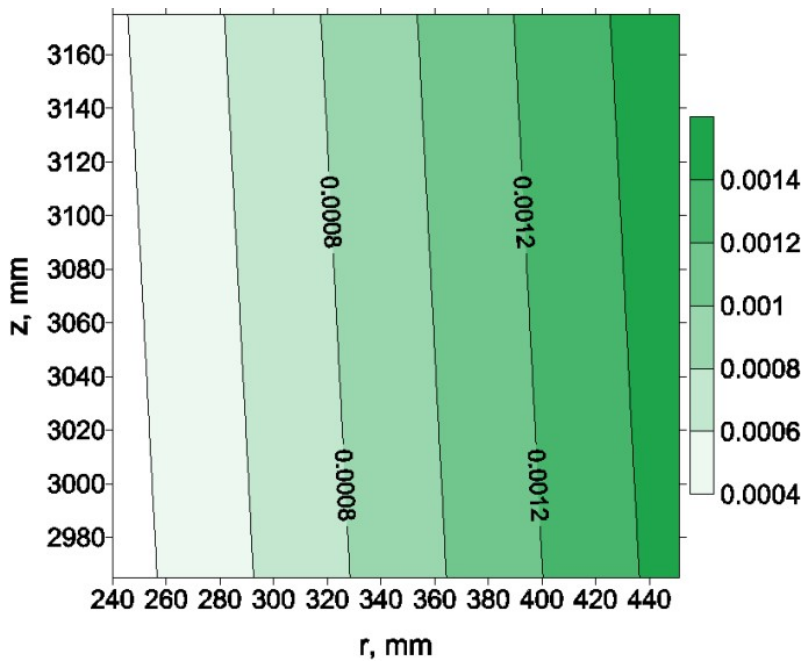

Fig. 34. The distribution of the effective logarithmic strain in the ingot 2-2 cross-section after tempering (Case II) 


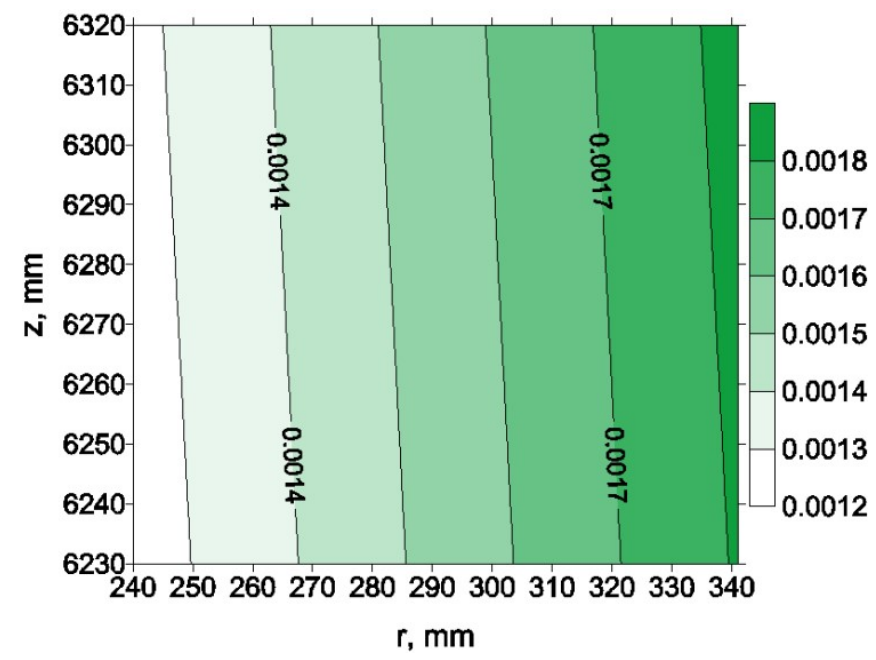

Fig. 35. The distribution of the effective logarithmic strain in the ingot 3-3 cross-section after tempering (Case II)

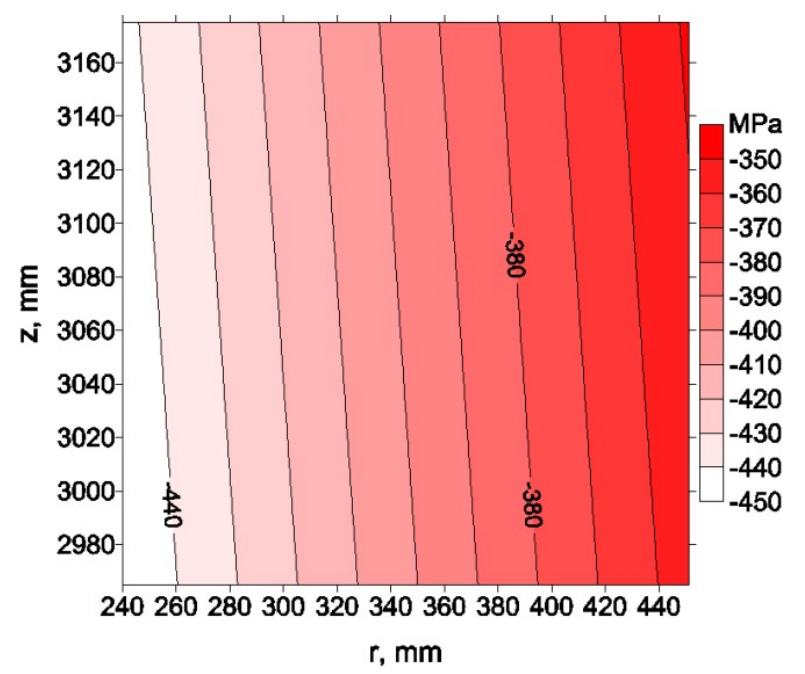

Fig. 37. The mean stress distribution in the ingot 2-2 cross-section after tempering (Case II)

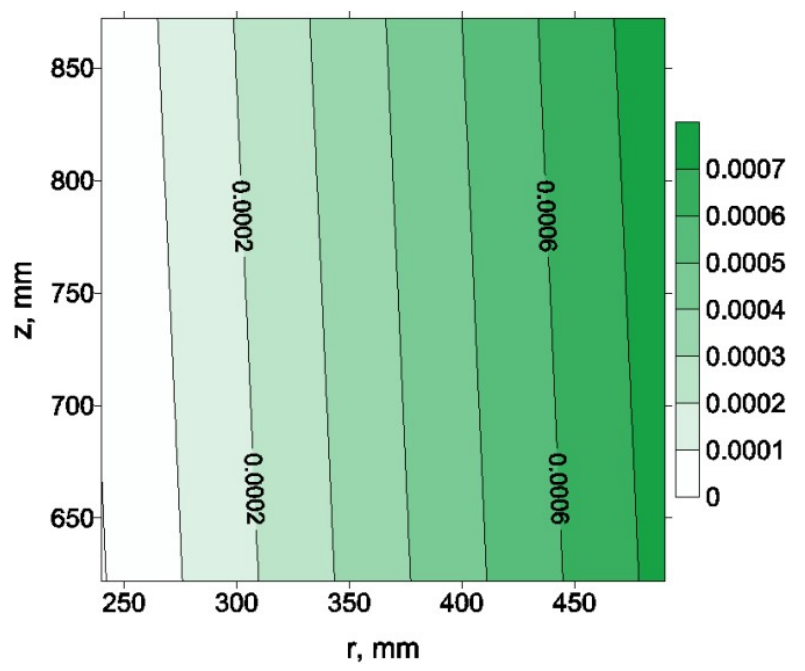

Fig.39. The distribution of the effective logarithmic strain in the ingot 1-1 cross-section after cooling in air (Case II)

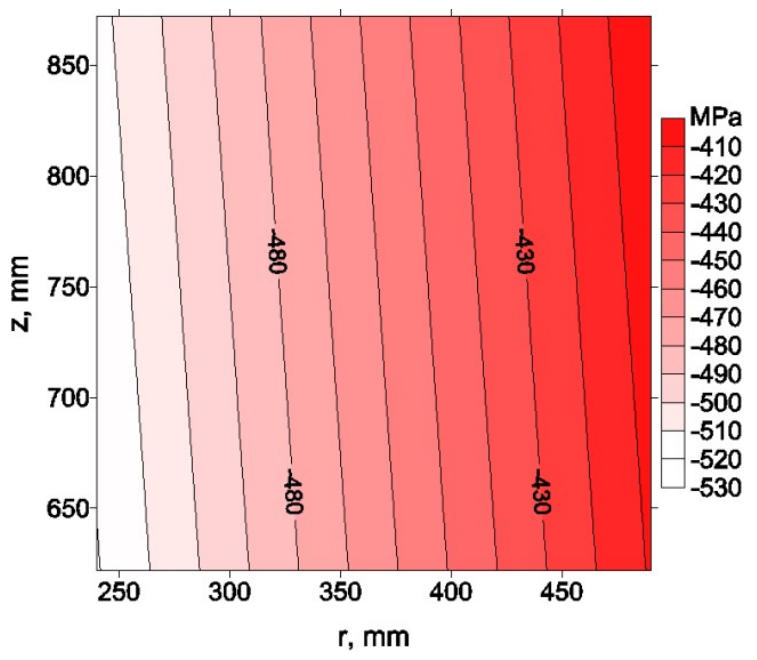

Fig. 36. The mean stress distribution in the ingot 1-1 cross-section after tempering (Case II)

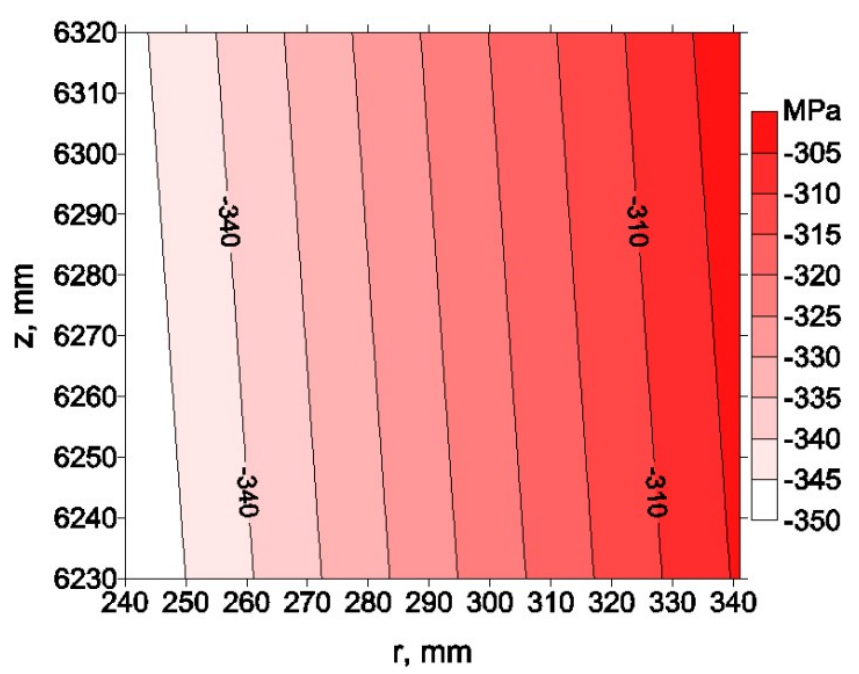

Fig.38. The mean stress distribution in the ingot 3-3 cross-section after tempering (Case II)

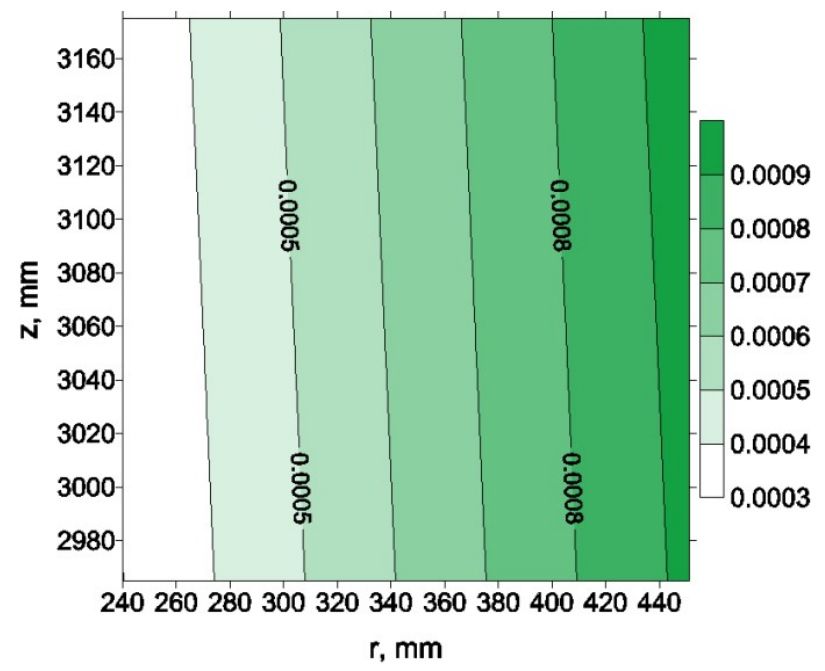

Fig. 40. The distribution of the effective logarithmic strain in the ingot 2-2 cross-section after cooling in air (Case II) 


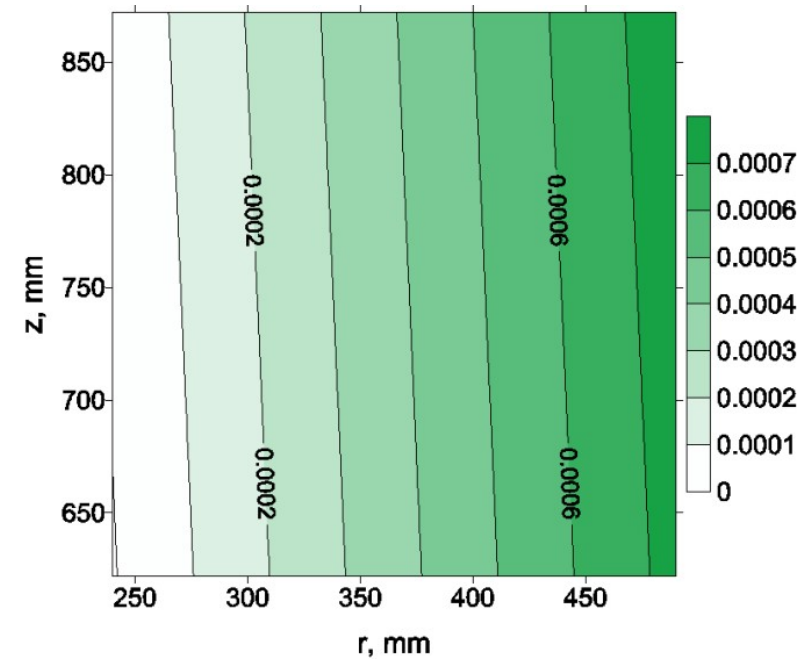

Fig. 41. The distribution of the effective logarithmic strain in the ingot 3-3 cross-section after cooling in air (Case II)

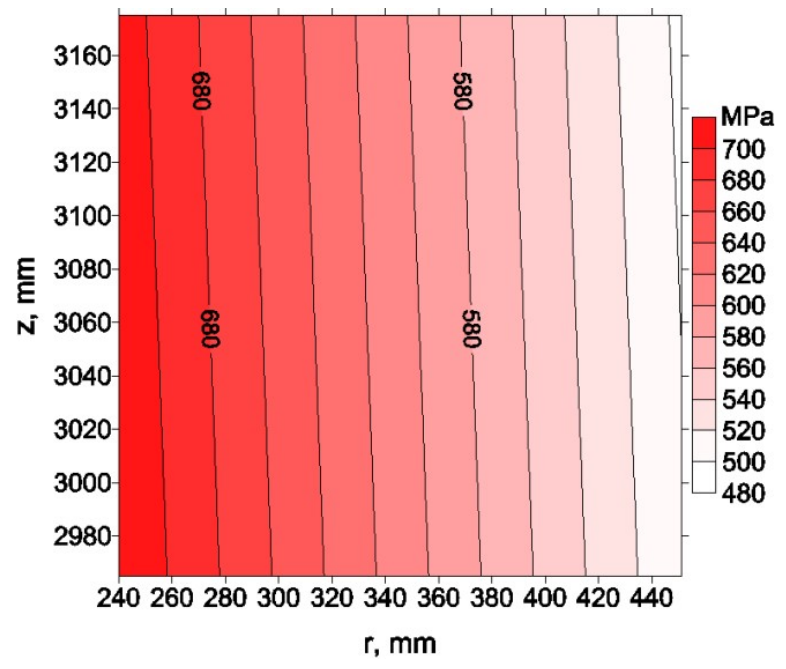

Fig. 43. The mean stress distribution in the ingot 2-2 cross-section during cooling in air (Case II)

stress values have not dropped below $-410 \mathrm{MPa}$ in 1-1 crosssection (Fig. 36). In case of 2-2 and 3-3 cross-sections have been much lower and not exceeded $-350 \mathrm{MPa}$ and $-305 \mathrm{MPa}$ respectively (Fig. 37-38). In the entire volume of the shaft mean stresses have been compressive. Time of the last heat treatment operation which was cooling in air was only 10 minute longer from that used in Case I (Tab. 1). The windmill shaft temperature after cooling in air was about $50^{\circ} \mathrm{C}$. The effective logarithmic strain has been slightly lower from that of Case I, here it has not exceed 0.001 at any cross-section of the ingot (Fig. 39-41). The maximum values of the mean stresses after the air cooling operation in Case II have been larger than those in Case I. For example the mean stress in the ingot 1-1 cross-section was equal to $800 \mathrm{MPa}$ near the internal surface of the ingot. The minimum value of the mean stress after heat treatment process has not dropped below $540 \mathrm{MPa}$.

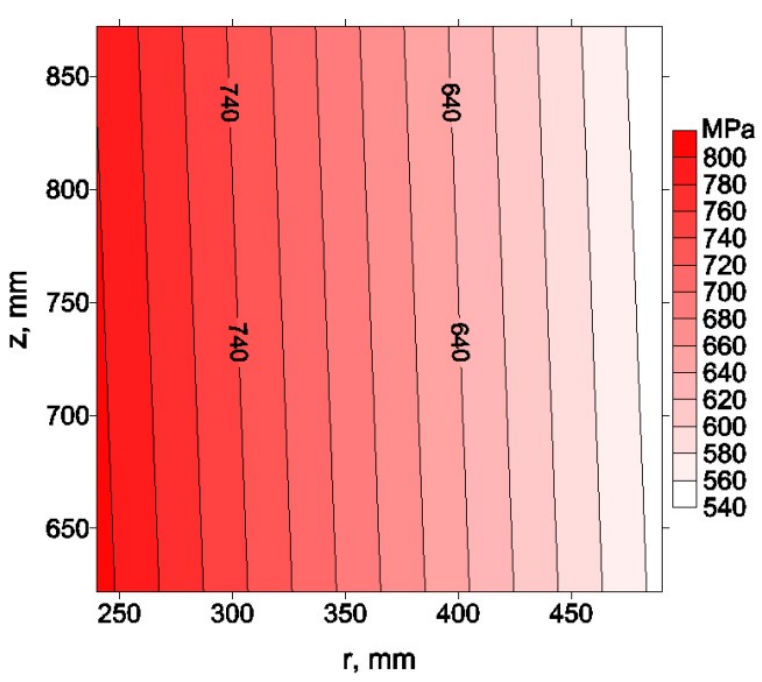

Fig. 42. The mean stress distribution in the ingot 1-1 cross-section during cooling in air (Case II)

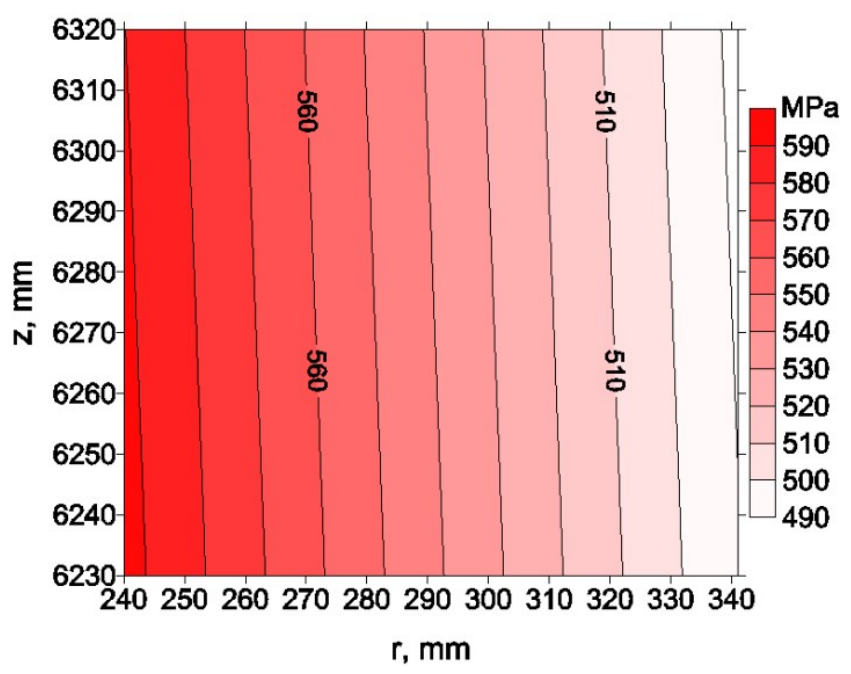

Fig. 44. The mean stress distribution in the ingot 3-3 cross-section during cooling in air (Case II)

\section{Conclusions}

In the paper the results of calculations which have allowed designing the heat treatment process of the windmill shaft have been presented. The two heat treatment processes have been considered. The processes consisted of four heat treatment operations. The processes has differed in the type of cooling medium used for quenching. The conducted analysis has allowed determining the time of each heat treatment operation required to obtain demanded properties of the windmill shaft. The simulations have allowed answering the question on a possibility of crack formation in the heat treated windmill shaft. For the calculation the self-developed software was utilized. The developed stresses and strains model can also be used to calculate the stress field in ingots and profiles. The developed stresses and strains model can also be used to calculate the stress field in ingots and other axially symmetric products. 


\section{Acknowledgements}

Scientific study financed from the regular activity of the Faculty of Metals Engineering and Industrial Computer Science of AGH University of Science and Technology.

\section{REFERENCES}

[1] I. Olejarczyk, A. Adrian, H. Adrian, B. Mrzygłód, Algorithm for controlling of quench hardening process of constructional steels, Achieves of Metallurgy and Materials 55, (1), 171-179 (2010).

[2] R.L.S. Otero, W.R. Otero, G.E. Otten, L.C.F. Canale, Quench factor characterization of steel hardening: A review, International Journal of Mechanical Engineering and Auromation 1, (3), 119128 (2014)

[3] T. Domański, A. Bokota, The numerical model to prediction of phase components and stresses distribution in hardened tool steel for cold work, International Journal of Mechanical Sciences 96-97, 47-57 (2015).

[4] A. Gołdasz, Z. Malinowski, T. Telejko, A. Buczek, A. Szajding, J. Nowak, G. Styczeń, Opracowanie krzywych nagrzewania w piecu pokrocznym z wykorzystaniem systemu Datapaq Slab Reheat System, Hutnik Wiadomości Hutnicze 4, 262-266 (2013).

[5] P.D. Hodgson, K.M. Browne, D.C. Collinson, T.T. Pham, R.K. Gibs, A Mathematical model to simulate the thermomechanical processing of steel, $3^{\text {rd }}$ International Seminar of the International Federation for Heat Treatment and Surface Engineering, Melbourne 139-159 (1991).

[6] A. Buczek, T. Telejko, Investigation of heat transfer coefficient during quenching in various cooling agents, International Journal of Heat and Fluid Flow 44, 358-364 (2013).

[7] B. Hadała, Implementation of the heat balance in the finite element solution to the temperature field of the plastically deformed material, International Journal of Thermal Sciences 71, 123-181 (2013).

[8] O.C. Zienkiewicz, Metoda elementów skończonych, 1972 Arkady, Warszawa.

[9] Z. Malinowski, Numeryczne modele w przeróbce plastycznej w wymianie ciepła, 2005 Uczelniane Wydawnictwa Naukowo-Dydaktyczne, Kraków.

[10] W.M. Garrison, N.R. Moody, Ductile fracture, J. Phys. Chem. Solids. 48, 1035-1074 (1987). 